\title{
Best-of-Three Contests: Experimental Evidence
}

\author{
Shakun D. Mago ${ }^{\mathrm{a}}$, Roman M. Sheremeta ${ }^{\mathrm{b}}$ and Andrew Yates ${ }^{\mathrm{a}}$ \\ ${ }^{a}$ Department of Economics, Robins School of Business, University of Richmond, \\ 28 Westhampton Way, Richmond, VA 23173, USA \\ ${ }^{\mathrm{b}}$ Argyros School of Business and Economics, Chapman University, \\ One University Drive, Orange, CA 92866, USA
}

December 7, 2010

\begin{abstract}
We conduct an experimental analysis of a best-of-three Tullock contest. Intermediate prizes lead to higher efforts, while increasing the role of luck (as opposed to effort) leads to lower efforts. Both intermediate prizes and luck reduce the probability of contest ending in two rounds. The patterns of players' efforts and the probability that a contest ends in two rounds is consistent with 'strategic momentum', i.e. momentum generated due to strategic incentives inherent in the contest. We do not find evidence for 'psychological momentum', i.e. momentum which emerges when winning affects players' confidence. Similar to previous studies of contests, we find significantly higher efforts than predicted and strong heterogeneity in effort between subjects.
\end{abstract}

JEL Classifications: C72, C91, D72

Keywords: best-of-three contest, experiments, strategic momentum, psychological momentum

Corresponding author: Shakun D. Mago; E-mail: sdatta@ richmond.edu

*We thank Tim Cason, Dan Kovenock, participants at the International Economic Science Association conference in Copenhagen and Economic Science Association conference in Tucson for helpful comments. University of Richmond provided funds for conducting the experiments. Any remaining errors are ours. 


\section{Introduction}

Many contests feature a best-of-N structure. An economic analysis of best-of-N contests offers several interesting predictions about the pattern of effort exerted by players during the various rounds of the contest. This, in turn, implies predictions about the pattern of outcomes for these contests. Much of the extant empirical literature focuses on sports contests. Because it is typically difficult to measure the actual effort expended by players in sports contests, almost all these studies focus solely on whether the pattern of outcomes is consistent with the theoretical predictions (Mosteller 1952; Jackson 1993; Ferrall and Smith, 1999; McFall et al. 2009; Page 2009; Malueg and Yates 2010). However, this methodology provides only an indirect measure of effort. In this paper, we use laboratory experiments to obtain direct empirical evidence on the pattern of effort and outcomes in a best-of-three contest.

Consider a best-of-three contest between two ex-ante symmetric players. The first player to win two rounds is the contest winner. Let the probability of winning a round be a function of the players' effort and luck. Economic theory suggests that both players will exert equal effort in the first round and equal effort again in the third round (if one occurs). In the second round, the relative efforts are determined by the parameters of the contest. In our baseline treatment, the winner of the first round has a higher effective value associated with winning the second round, and hence will exert more effort. Translating effort into outcomes implies that both players are equally likely to win the first round. The winner of the first round is more likely to win the second round; but if the contest goes to the third round, then both players are once again equally likely to win. Thus, the outcome of the first round has an asymmetric effect on the second round efforts by ex-ante symmetric players, and equilibrium play explains the emergence of 'hot hand' (winning streak that occurs more often than predicted by chance). We say that the winner of the 
first round exhibits 'strategic momentum' in the second round to reinforce the idea that this increase in the probability of winning is a consequence of the strategic incentives inherent in the contest.

In addition to strategic momentum, players in a best-of-three contest may also exhibit 'psychological momentum.' There is no single definition of psychological momentum, but it is often based on the maxim 'success breads success,' i.e., winning a round affects players' confidence and makes them more likely to win the next round (Baker, Gibbs and Homstrom, 1994a, 1994b; Dorsey-Palmeteer and Smith, 2004, Vallerand et al., 1988; Kerick et al., 2000). Given their varying impact on effort choices and outcomes, it is important to distinguish between strategic and psychological momentum. Our first piece of evidence to distinguish between the two momentums lies in the structure of the best-of-three contest itself. Specifically, in the third round the optimal strategy for both players is to exert equal effort (no strategic momentum). However, if we observe that the winner of the second round is more likely to win the third round, then this is evidence in support of psychological momentum. To obtain additional validation, we employ a treatment with parameters such that there is no strategic momentum in any round. In this case, if we observe that the winner of the first round is more likely to win the second round, then again this is evidence in support of psychological momentum.

Our experimental design also encompasses comparative statics for two treatment variables. The first variable is an intermediate prize for winning an individual round. Theory predicts that intermediate prizes leads to an increase in effort, and a decrease in the probability of contest ending in two rounds. The second treatment variable is the degree to which luck rather than effort determines the winner of a round. Theory predicts that an increase in the role of luck leads to a decrease in effort and a decrease in the probability of contest ending in two rounds. 
Existing experimental studies of contests investigate a diverse array of issues such as entry costs, player asymmetry, effect of carryover, risk aversion, multiple prizes, etc (e.g., Millner and Pratt, 1989, 1991; Potters et al., 1998; Davis and Reilly, 1998; Anderson and Stafford, 2003; Schmitt et al., 2004; Fonseca, 2009; Anderson and Freeborn, 2010; Sheremeta, 2010a). However, most experimental studies consider contests lasting only one round. Studies on multiple round contests are few and relatively recent. For instance, Zizzo (2002) examines the aggressiveness of players in a multi-stage patent race. Sheremeta (2010b) compares expenditures in a multi-round elimination contest to a single-round contest. We extend the literature by examining patterns of effort and outcomes in a contest with the best-of-three structure. We also contribute to the theoretical literature by analyzing the impact of intermediate prizes, and test the comparative statics predictions with respect to both intermediate prizes and luck.

Almost without exception, the existing experimental studies provide evidence of contest expenditure that is in excess of Nash equilibrium levels, but which is consistent with various models' comparative statics results. Our results fall in line with this general trend. We find strong support for our comparative statics predictions, but we also find significantly higher efforts than predicted and strong heterogeneity in effort between subjects. We discuss a number of possible explanations for these findings. Finally, and perhaps most importantly, our results for the pattern of efforts and outcomes are consistent with strategic momentum. We do not find any evidence for psychological momentum.

\section{Theoretical Model}

Before analyzing a best-of-three contest, it is useful to review a single round Tullock contest. There are two risk-neutral, equally-skilled players $i$ and $j$. The players select effort $x_{i}$ and 
$x_{j}$ to win the contest. The contest success function $p\left(x_{i}, x_{j}\right)$ specifies the probability that player $i$ wins the contest as a function of players' efforts. Following Tullock (1980), we have

$$
p\left(x_{i}, x_{j}\right)=x_{i}^{r} /\left(x_{i}^{r}+x_{j}^{r}\right) .
$$

The exponent $r$ can be interpreted as the 'decisiveness parameter' (Hirshleifer, 1995) or the 'contest intensity' (Weimann et al., 2000), and reflects how sensitive the probability of winning is to the players' relative expenditure. It can also be interpreted as the degree of 'luck' in the contest. As $r$ decreases, luck plays a more important role. As $r$ approaches zero, each player wins a given round with probability $1 / 2$, regardless of effort. We assume that $0<r \leq 1$ which ensures that the contest success function is concave in a player's expenditure and that a unique pure strategy Nash equilibrium exists.

If player $i$ 's value for winning the contest is $V$ and player $j$ 's value for winning the contest is $W$ then the expected payoff to player $i$ is

$$
E\left(\pi_{i}\right)=p V-x_{i}
$$

and the expected payoff to player $j$ is

$$
E\left(\pi_{j}\right)=(1-p) W-x_{j} .
$$

That is, the probability of winning times the value of the prize minus the effort expended. Following Malueg and Yates (2005), we can write the Nash equilibrium efforts as

$$
x_{i}^{*}=r \rho^{r} V /\left(1+\rho^{r}\right)^{2} \text { and } x_{j}^{*}=r \rho^{r} W /\left(1+\rho^{r}\right)^{2},
$$

where $\rho=W / V$ is the ratio of players' value of winning the contest. Note that the ratio of players' efforts is equal to the ratio of their values.

Returning to a best-of-three contest, players $i$ and $j$ face each other in as many as three successive rounds. ${ }^{1}$ The first player to win two rounds is the contest winner. In each round,

\footnotetext{
${ }^{1}$ Klumpp and Polborn (2006) provide a theoretical analysis of a best-of-three contest. We extend their work by including intermediate prizes.
} 
players select efforts $x_{i}$ and $x_{j}$. The probability that player $i$ wins a round is given by (1). Both players value winning the contest at $v$, and there is an additional intermediate prize $d$ for winning individual rounds. To characterize the players' effort choices, we apply backward induction. Let $V_{i}(m, n)$ be the expected payoff to player $i$ when player $i$ needs to win $m$ more rounds to win the contest and player $j$ needs to win $n$ more rounds to win the contest.

The backward induction argument starts with the third round. Here, both players have won one round each. The winner of the third round receives the final prize $v$ for winning the overall contest, and an intermediate prize $d$ for winning the third round. The loser of the third round receives 0 . Therefore the expected payoff for player $i$ in the third round is given by

$$
V_{i}(1,1)=p\left(v+d-x_{i}\right)+(1-p)\left(-x_{i}\right)=p(v+d)-x_{i}
$$

and the expected payoff for player $j$ in the third round is given by

$$
V_{j}(1,1)=(1-p)\left(v+d-x_{j}\right)+p\left(-x_{j}\right)=(1-p)(v+d)-x_{j} .
$$

This is equivalent to a single-round Tullock contest in which player $i$ 's value of winning is $V=v$ $+d$ and player $j$ 's value of winning is $W=v+d$. From (2), the third round Nash equilibrium efforts are

$$
x_{1}^{*}=x_{2}^{*}=r(v+d) / 4
$$

Both players exert equal effort because they have the same value for winning the round. Their expected payoffs can be found by substituting these expressions back into the equations for $V_{i}(1,1)$ and $V_{j}(1,1)$.

Next we take a step backwards to analyze the second round. One player will have won the first round and the other will have lost. Without loss of generality, assume that player $i$ has won and player $j$ has lost the first round. If player $i$ wins the second round the contest concludes; player $i$ receives the final prize $v$ for winning the overall contest and an intermediate prize $d$ for 
winning the second round while player $j$ receives zero. If, however, player $j$ wins the second round the contest moves to the third round, and player $i$ receives the third round expected payoff $V_{i}(1,1)$ while player $j$ receives an intermediate prize $d$ and the third round expected payoff $V_{j}(1,1)$. Therefore, the expected payoff for player $i$ in the second round is

$$
V_{i}(1,2)=p\left(v+d-x_{i}\right)+(1-p)\left(V_{i}(1,1)-x_{i}\right)=V_{i}(1,1)+p\left(v+d-V_{i}(1,1)\right)-x_{i},
$$

and the expected payoff for player $j$ in the second round is

$$
V_{i}(1,2)=(1-p)\left(d+V_{j}(1,1)-x_{j}\right)+p\left(-x_{j}\right)=(1-p)\left(V_{j}(1,1)+d\right)-x_{j} .
$$

This is equivalent to a single-round Tullock contest in which player $i$ 's value of winning is $V=v$ $+d-V_{i}(1,1)$ and player $j$ 's value of winning is $W=d+V_{j}(1,1) .{ }^{2}$ The Nash equilibrium efforts in the second round can be found by substituting these values into (2). If the intermediate prize is zero, then it is easy to show player $i$ has a higher value of winning the second round than player $j$. This in turn implies that player $i$ will exert greater effort than player $j$, and accordingly, is more likely to win the second round (and the overall contest). For other values of intermediate prize ( $d$ $>0$ ), it is possible for both players to exert equal effort, or for player $j$ to exert more effort than player $i$. In cases where player $i$ exerts more effort than player $j$, we have strategic momentum. ${ }^{3}$ By symmetry, if player $i$ has lost rather than won the first round, then

$$
V_{i}(2,1)=V_{j}(1,2) \text { and } V_{j}(2,1)=V_{i}(1,2)
$$

Finally, we consider the first round. If player $i$ wins the first round, she receives the intermediate prize $d$ and the expected payoff $V_{i}(1,2)$. If player $i$ loses the first round, she receives the expected payoff $V_{i}(2,1)$. Therefore, the expected payoff for player $i$ in the first round is

$$
V_{i}(2,2)=p\left(d+V_{i}(1,2)-x_{i}\right)+(1-p)\left(V_{i}(2,1)-x_{i}\right)=V_{i}(2,1)+p\left(d+V_{i}(1,2)-V_{i}(2,1)\right)-x_{i}
$$

and the expected payoff for player $j$ in the first round is

\footnotetext{
${ }^{2}$ Note that the value $V_{i}(1,1)$ is the expected payoff in round 3 and does not depend on the effort $x_{i}$ in the current round.

${ }^{3}$ Strategic momentum exists if $d>r v /(2-r)$.
} 


$$
V_{j}(2,2)=(1-p)\left(d+V_{j}(2,1)-x_{j}\right)+p\left(V_{j}(1,2)-x_{j}\right)=V_{j}(1,2)+(1-p)\left(d+V_{j}(2,1)-V_{j}(1,2)\right)-x_{i}
$$

This is equivalent to a single round Tullock contest in which $V=\left(d+V_{i}(1,2)-V_{i}(2,1)\right)$ and $W=$ $\left(d+V_{j}(2,1)-V_{j}(1,2)\right)$. Using $(10)$, we see that $V=W$. Once again players have equal values for winning the round and so they exert equal effort in the first round. ${ }^{4}$

The theoretical model illustrates how strategic momentum results from equilibrium play. However, laboratory experiments feature human subjects who may also experience psychological momentum. Psychological literature suggests that psychological momentum can be bi-directional (e.g. Vallerand et al., 1988; Kerick et al., 2000). This means that the 'encouraged' winner of a given round may experience positive psychological momentum and the 'discouraged' loser may experience negative psychological momentum. A simple way to incorporate this idea into a best-of-three contest is to assume that psychological momentum leads the winner of a given round to exert more effort in the next round than the loser of a given round. Thus, psychological momentum may occur in both the second and third round, regardless of the underlying parameter values.

\section{Experimental Environment}

\subsection{Experimental Design and Hypotheses}

Table 1 summarizes the experimental parameters. We employ three features: "H" denotes a high exponent in the contest success function, "L" denotes a low exponent, and "I" denotes an intermediate prize. In our baseline HI treatment, the success exponent is high $(r=1)$ and there is an intermediate prize for winning an individual round $(d=25)$. We include two control

\footnotetext{
${ }^{4}$ Also note that although the players are symmetric both in round 1 and round 3 , their value of winning the first round is lower than the value of winning the third and final round. Therefore, if the contest goes to the third round, both players exert greater effort than in earlier rounds.
} 
treatments. First, to analyze the impact of intermediate prize we include the $\mathrm{H}$ treatment. In the $\mathrm{H}$ treatment, there is no intermediate prize $(d=0)$, otherwise it is identical to the HI treatment. Second, to analyze the impact of luck we consider an alternative value for the exponent $r$. In the LI treatment, the exponent is low $(r=0.4)$, otherwise it is identical to the HI treatment. In all three treatments the value of the final prize is $v=100$ experimental francs. Table 1 presents the equilibrium efforts in each round, the expected payoffs, and the probability of contest ending in two rounds for all three treatments.

The theoretical predictions in Table 1 suggest several hypotheses. The first two concern comparative statics:

Hypothesis 1: Comparing HI versus H treatment, (a) intermediate prizes lead to higher effort in all rounds by both players; (b) intermediate prizes reduce the probability of contest ending in two rounds.

Hypothesis 2: Comparing HI versus LI treatment, (a) lower $r$ leads to lower effort in all rounds by both players; (b) lower $r$ reduces the probability of contest ending in two rounds.

The next two hypotheses concern the features of strategic momentum:

Hypothesis 3: In HI and $\mathrm{H}$ treatments, (a) round 1 winner exerts more effort in round 2 than round 1 loser. In LI treatment, (b) both winner and loser of round 1 exert the same effort in round 2 .

Hypothesis 4: In all treatments, round 2 winner exerts the same effort in round 3 as round 2 loser.

Note that evidence in favor of Hypothesis $3 \mathrm{~b}$ and Hypothesis 4 provides evidence against psychological momentum. 


\subsection{Experimental Procedures}

A total of 108 subjects participated in nine sessions with 12 subjects per session. All subjects were undergraduate students at Chapman University. Subjects participated in only one session of this study, although some subjects had previously participated in other unrelated economics experiments.

The experiment was programmed and conducted with the software z-Tree (Fischbacher, 2007). No communication between subjects was permitted and all choices and information were transmitted via computer terminals. Each experimental session proceeded in two parts: a risk assessment part and a best-of-three contest part. Subjects were given the instructions, available in the Appendix, at the beginning of each part. The experimenter read the instructions aloud, so the information contained therein is assumed to be common knowledge. Subjects then completed an online quiz to verify their understanding of the instructions. The experiment started only after all subjects had completed the quiz, and explanations were provided for any incorrect answers. In the risk assessment part of the experiment, subjects made 15 choices in simple lotteries, similar to Holt and Laury (2002). This method was used to elicit subjects' risk preferences. In the contest part of the experiment, subjects participated in 20 periods of play in one of the three treatments. In each period, subjects were randomly and anonymously placed into 6 groups with 2 players in each group. In each round subjects made their bids (no more than 200 francs) and after all subjects submitted their bids, the computer chose the winner of that round by implementing a lottery with probabilities defined by the relevant contest success function. All subjects were informed that by increasing their bids, they would increase their chance of winning the round and that, regardless of who wins the round, all subjects would have to pay their bids. At the end of each round the computer displayed own bid, opponent's bid, and the result of the lottery draw. A 
period lasted for either two or three rounds. The period ended when one of the players in the group won two rounds. At the end of each period subjects were subjects were randomly regrouped to form new two-player groups.

At the end of the experiment, 2 out of 20 periods in the contest part of the experiment were randomly selected for payment. The sum of the earnings for these 2 periods was exchanged at rate of 25 experimental francs = US $\$ 1$. Subjects were also paid for 1 out of the 15 decisions made in the risk assessment part of the experiment. All subjects received an initial endowment of $\$ 15$ to cover potential losses. On average, subjects earned $\$ 20$ each, which was paid anonymously and in cash. The experimental sessions lasted about 90 minutes.

\section{Results}

\subsection{Comparative Statics Results}

Table 2 summarizes the average effort in each round, total effort and payoffs, and the likelihood of contest ending in two rounds. Figure 1 displays the time series of average total effort over all 20 periods. Consistent with other experimental studies of contests we find persistent and significant over-dissipation in all three treatments. In Section 4.3, we explore the possible reasons for this over-dissipation. Note that although subjects expend significantly more effort than predicted, aggregate effort patterns remain sensitive to the Nash prediction. Comparing across treatments, total effort in all three treatments is in qualitative agreement with the equilibrium predictions (average total effort is 76.3 in HI, 60.8 in $\mathrm{H}$ and 58.2 in LI). Based on the estimation of a random-effect model with standard errors clustered at session level and subject-level random effects, we find that the total effort expended in the HI treatment is significantly higher than the effort expended in the $H$ treatment ( $p$-value $<0.01$ ) and the LI 
treatment ( $\mathrm{p}$-value $<0.01$ ). This finding lends strong empirical support for Hypothesis 1a and 2a. Nevertheless, it is important to note that the observed effort does not fall in proportion to the predicted level. Comparing $\mathrm{HI}$ and $\mathrm{H}$ treatment, total effort is predicted to be $37 \%$ lower in the $\mathrm{H}$ treatment but is actually only $20 \%$ lower. The comparison for HI and LI treatment yields even bigger differences. Effort in the LI treatment is predicted to be $58 \%$ lower than the HI treatment, but the decrease in effort is less than half of prediction (24\%).

Result 1: Intermediate prizes lead to significantly higher effort by both players (HI vs. H) while lower $r$ leads to significantly lower effort (HI vs. LI).

Theory also predicts that intermediate prizes and exponent $r$ influence the probability of contest ending in two rounds. In qualitative agreement with the equilibrium predictions, data indicates that the probability of contest ending in round 2 decreases with intermediate prizes (0.61 in $\mathrm{H}$ vs. 0.58 in $\mathrm{HI}$ ) and with lower $r(0.58$ in $\mathrm{HI}$ vs. 0.51 in $\mathrm{LI})$. Based on estimation of a random-effect probit model with subject-level random effects, we find that the difference is significant when comparing HI and LI treatment (p-value < 0.05), but not when comparing $\mathrm{H}$ and $\mathrm{HI}$ treatment $(\mathrm{p}$-value $=0.2$ ). This finding lends partial empirical support to Hypothesis $1 \mathrm{~b}$ and $2 b$.

Result 2: The probability of contest ending in two rounds is significantly lower with lower $r$ (HI vs. LI), but is not significantly lower with intermediate prizes (HI vs. H)

\subsection{Strategic and Psychological Momentum}

Table 2 and Figures 2, 3 and 4 display the average effort choices by players in each of the three rounds. Theory predicts that in the $\mathrm{HI}$ and $\mathrm{H}$ treatments, winner of round 1 should have strategic momentum (Hypothesis 3). We find strong support for this in the data. Effort in round 2 
by the winner of round 1 exceeds that of the loser (HI: p-value $<0.05$ and H: p-value $<0.01$ ). Accordingly, the likelihood that round 1 winner wins the overall contest remains greater than 50 percent in both treatments (HI: 58 and H: 61 percent). Of course, it is possible that part or all of this momentum in round 2 of the $\mathrm{HI}$ and $\mathrm{H}$ treatments is due to psychological momentum. The second round of the LI treatment offers a more discriminating test. Here, theory predicts no strategic momentum in round 2 , i.e. the outcome of round 1 does not influence either player's effort choices in round 2. However, if psychological momentum is present then the round 1 winner should expend higher effort than the loser. Our data indicates that effort chosen by round 1 winner in round 2 is not significantly different from that chosen by round 1 loser (24.4 vs. 23.3, p-value $=0.16$ ). This means that round 1 winner is no more likely to win round 2 . Our finding that the probability of contest ending in round 2 remains close to prediction ( 51 vs. 50 percent) is consistent with this result, suggesting no psychological momentum in round 2 of the LI treatment. 5

Result 3: In $\mathrm{HI}$ and $\mathrm{H}$ treatments, effort in round 2 by round 1 winner is significantly higher than effort by round 1 loser, so the contest is more likely to end in two rounds. In LI treatment, effort in round 2 by round 1 winner is not significantly different from the effort by round 1 loser, so the contest is equally likely to end in two rounds as in three.

Turning to round 3 , theory predicts there should not be any strategic momentum. Both players should exert the same effort in round 3 (Hypothesis 4). However, there may be psychological momentum, as success or failure in the second round may affect players in the third round. Using panel data analysis with subject specific random effects and robust standard

\footnotetext{
${ }^{5}$ These results are further substantiated by probit models that include subject random effects, session fixed effects and a time trend. We find that in $\mathrm{HI}$ and $\mathrm{H}$ treatments, the likelihood of winning round 2 is higher for round 1 winner ( $\mathrm{p}$-value < 0.01 ); but in case of LI treatment, round 1 winner is no more likely to win round 2 than round 1 loser $(\mathrm{p}$-value $=0.45)$.
} 
errors, we find no difference in the round 3 effort chosen by the winner of round 2 compared to the loser of round $2(\mathrm{H}: \mathrm{p}$-value $=0.61 ; \mathrm{HI}: \mathrm{p}$-value $=0.21 ; \mathrm{LI}: \mathrm{p}$-value $=0.31)$. This again suggests lack of psychological momentum.

Result 4: In all treatments, effort in round 3 by round 2 winner is not significantly different than effort by round 2 loser.

Taken together, Results 3 and 4, allow us to convincingly state that the momentum in the second round of the $\mathrm{HI}$ and $\mathrm{H}$ treatments, which results in a greater likelihood of the contest ending in two rounds, is a result of strategic considerations and not psychological impetus.

\subsection{Over-dissipation}

At the beginning of Section 4.1, we noted a striking feature of the data: in all three treatments, subjects over-expend effort relative to the risk-neutral Nash predictions. As is evident from Table 2 and Figure 1, the magnitude of this difference is large and persistent over time. In the $\mathrm{H}$ and LI treatments, average total effort is around twice the equilibrium prediction $(\mathrm{H}: 60.8$ versus 32; LI: 58.2 versus 21.3), and in the HI treatment average total effort is about 50 percent larger (76.3 versus 50.5). ${ }^{6}$ Such over-dissipation is not uncommon in experimental literature on contests and similar findings are also reported in Davis and Reilly (1998), Potters et al. (1998), and Sheremeta (2010a, 2010b). One simple explanation for over-dissipation is inexperience. For example, Davis and Reilly (1998) show that overbidding decreases but does not disappear with

\footnotetext{
${ }^{6}$ To find empirical support for these conclusions we estimated a simple panel regression separately for each treatment over all 20 periods. The random effects model included total effort as the dependent variable and a constant and a time trend as the independent variables. The model included random efforts error structure (individual subjects) and the standard errors were clustered at the session level. A standard Wald test, conducted on the estimates of the model, finds that for all treatments the constant coefficients are significantly higher than the predicted theoretical values ( $\mathrm{p}$-value $<0.01$ ). If we restrict the analysis to last 10 periods (where the behavior has stabilized), the over-dissipation result holds for the HI and LI treatment (p-value < 0.05), but effort in the $\mathrm{H}$ treatment is not different from prediction ( $\mathrm{p}$-value $=0.2$ ).
} 
time. Regression using data for all 20 periods show that the coefficient on a time trend (1/period) is positive and significant, which suggests that individual learning is taking place, and that with repetition subjects expend lower efforts. ${ }^{7}$ This is also evident in Figure 1. Nevertheless, the difference between predicted and observed effort level remains significant even in the last 5 periods ( $\mathrm{p}$-value $<0.01$ ). As a result of this over-dissipation, the observed payoffs in all three treatments are significantly lower than expected $(\mathrm{p}$-value $<0.01)$.

Result 5: There is significant aggregate over-dissipation in all treatments. The level of over-dissipation decreases over time, but remains positive and significant.

Furthermore, it is important to note that while over-dissipation does not distort the qualitative comparative statics results (Results 1 and 2), it does influence the quantitative analysis. For example, when testing Hypotheses 1 and 2, we observed that the effort does not fall in proportion to the predicted level. Also, contrary to the prediction of a substantial drop in effort by round 1 loser, we find that both round 1 winner and loser increase their effort in round 2 . This over-dissipation in round 2 efforts by both players can explain why equilibrium over-predicts the probability of the contest ending in two rounds (HI: 63 vs. 58 and H: 75 vs. 61).

There are a number of other explanations for over-dissipation in contests. One common explanation is that most subjects are likely to make mistakes (Lim et al., 2010; Sheremeta, 2010a). Bullock and Rutstrom (2007) and Sheremeta (2010a) show how quantal response equilibrium (McKelvey and Palfrey, 1995), which accounts for individual errors, can explain some of the over-dissipation observed in lottery contests. Another explanation for overdissipation is based on the evolutionary argument (Leininger, 2003; Hehenkamp et al., 2004; Riechmann, 2007). Evolutionary behavior postulates that players aim to beat each other, i.e. the tenet of 'rational payoff maximization' is replaced by 'relative payoff maximization.' For a two-

\footnotetext{
${ }^{7}$ If we restrict the analysis to last 10 periods, time trend is significant only for the LI treatment (p-value $<0.05$ ).
} 
player single-round Tullock contest, the effort in an evolutionary stable equilibrium is twice the effort in the Nash equilibrium (Hehenkamp et al., 2004; Lim et al., 2010). ${ }^{8}$ Another oft-cited explanation is based on judgmental biases and misperception of probabilities (Baharad and Nitzan, 2008; Sheremeta and Zhang, 2010). Many studies on individual behavior provide evidence that subjects misperceive probabilities in a systematic way - they assign over-weight to lower probability of winning and under-weight to higher probability of winning (Prelec, 1998, Wu and Gonzales, 1996; Tversky and Kahneman, 1992). This misperception and the resulting errors are explored by Parco et al. (2005) and Amaldoss and Rapoport (2009) as an explanation for observed over-dissipation in lottery contests. Finally, recent experiments have found evidence that subjects have a non-monetary utility of winning a Tullock contest, and this can partially explain overdissipation of effort (Parco et al., 2005; Amaldoss and Rapoport, 2009; Sheremeta, 2010b). ${ }^{9}$

All the above arguments can at least partially explain the over-dissipation documented in Result 5. However, we also provide an additional explanation for over-dissipation that is specific to our experiment: the sunk cost hypothesis. In an economic analysis of a best-of-three contests, effort expenditures in earlier rounds are sunk costs. Therefore, rational subjects should not let these previous expenditures affect their effort choices in current rounds. Evidence from various behavioral studies, however, suggests otherwise (Arkes and Blumer, 1985; Friedman et al. 2010). ${ }^{10}$ In our experiment, subjects who get to the third round have already expended some

\footnotetext{
${ }^{8}$ This quest to seek higher (expected) payoff than others is consistent with 'spite effect' contended by Hamilton (1970) or 'survival of the fittest' contended by Alchian (1950). Vriend (2000) and Reichmann (2006) show that learning by imitation of successful others is also equivalent to maximizing relative payoffs.

${ }^{9}$ Sheremeta (2010b) provides evidence for such non-monetary utility, by documenting that about $50 \%$ of subjects are willing to exert positive effort (thereby incurring monetary costs) in order to be the winner of a contest with the prize value of 0 .

${ }^{10}$ In the literature, the mechanism underlying this 'irrational escalation of commitment' is attributed to cognitive dissonance (Festinger, 1957), self-justification (Aronson, 1968) and prospect theory or loss aversion (Tversky and Kahneman, 1979).
} 
positive effort in the previous two rounds. If the sunk cost hypothesis is true, subjects who expend more effort in rounds 1 and 2 are also more likely to expend higher effort in the final decisive round. Based on a simple random effect regression, we find that there is a positive relationship between effort in round 3 and total effort in the previous two rounds (p-value < 0.01). This holds true irrespective of whether we use aggregate or treatment-specific data. Therefore, the sunk cost hypothesis may partially account for over-dissipation in our experiment.

\subsection{Heterogeneous Behavior}

Figure 5 displays the total effort of individual subjects in all three treatments. Contrary to a unique pure-strategy Nash prediction, there is substantial variation in effort choices across subjects. For instance, in the LI treatment, total effort is predicted to be 21.3, but instead the individual effort choices range from 26.5 to 102.4 . Similar behavior is observed in the $\mathrm{HI}$ and $\mathrm{H}$ treatment.

Result 6: There is strong heterogeneity in effort between subjects.

A common explanation is that individual efforts are heterogeneous because subjects who make these effort choices have heterogeneous preferences. Following Millner and Pratt (1991) and Sheremeta (2010a), we postulate that, to some extent, heterogeneity in effort in our experiment can be explained by heterogeneity in individual risk preferences. Recall that in the first part of our experiment, subjects participated in a simple lottery choice experiment that was designed to elicit a measure of risk aversion. The experiment contained 15 lottery choices subjects were asked to state whether they preferred safe option A or risky option B. Option A yielded $\$ 1$ payoff with certainty, while option $B$ yielded a payoff of either $\$ 3$ or $\$ 0$. The 
probability of receiving $\$ 3$ or $\$ 0$ varied across all 15 lotteries. ${ }^{11}$ These probabilities were structured such that the expected payoff of the safe option A exceeded that of the risky option B for the first 7 decisions, while option B had a higher payoff for the last 8 decisions. Therefore, a risk-averse subject will choose option A more than 7 times while a risk-seeking subject will choose option A fewer than 7 times. Following Holt and Laury (2002), we use the point at which subjects switch from the safe option to the risky option to define a range of values for the risk aversion parameter. These ranges are reported in Table 3 for a constant relative risk aversion utility function. Our subject pool is typical in the sense that a majority of our subjects show a tendency towards risk-averse behavior (HI: 72 percent, H: 77.9 percent; LI: 76.2 percent).

Table 3 also displays the treatment-specific average effort corresponding to the number of safe choices made by the subjects. In the theoretical literature, the effect of risk aversion on effort in contests is ambiguous and depends on the assumptions of the model. ${ }^{12}$ Random effects regressions that control for subject-level effect and cluster on sessions collaborate with this. In the $\mathrm{H}$ treatment, total effort is negatively correlated with the number of safe choices, thereby indicating that risk-averse subjects expend less effort. This observation is consistent with findings of other contest experiments where $r=1$ (Millner and Pratt, 1991; Anderson and Freeborn, 2009; Sheremeta, 2010a). Inclusion of intermediate prizes, however, dilutes the impact of risk aversion, and the coefficient on risk aversion is marginally negative and insignificant for the HI treatment. Finally, in the LI treatment, where luck plays a relatively large role, we find that risk averse players expend more effort ( $\mathrm{p}$-value $<0.05)$. Therefore, the differences in risk

\footnotetext{
${ }^{11}$ The first lottery offered a $0 \%$ chance of winning $\$ 3$ and a $100 \%$ chance of winning $\$ 0$, while the last lottery offered a $70 \%$ chance of winning $\$ 3$ and a $30 \%$ chance of winning $\$ 0$.

${ }^{12}$ Hillman and Katz (1984) showed that risk averse players should expend lower effort than risk neutral players, and risk seeking players should exert higher effort. Treich (2009) established that risk aversion always reduces effort if risk averse players are also 'prudent'. Nitzan (1991) showed that if agents are risk averse, the degree of underdissipation is inversely related to the degree of risk aversion. Konrad and Schlesinger (1997), on the other hand, showed that "it is possible for the contest with risk-averse players to dissipate more of the rents than the same contest with risk-neutral players" (Konrad and Schlesinger, 1997, p. 1677).
} 
preferences and the fact that such preferences are correlated with effort decisions, may explain some of the heterogeneity in effort between subjects.

\section{Conclusion}

In this paper, we use controlled laboratory environment to investigate the pattern of outcomes and efforts in a best-of-three contest that includes both intermediate prizes and a varying role of luck. Consistent with the theoretical predictions, we find that instituting intermediate prizes increases both the individual effort and the length of the contest. Conversely, players are unwilling to expend higher effort when luck plays an increasingly greater role in determining the winner. We observe strategic momentum in situations for which it is predicted, and we do not observe psychological momentum.

Our experiment provides direct empirical evidence that can be instructive in the design of optimal contests. Contest design has been a topic of extensive theoretical and empirical investigation primarily because contest objectives vary greatly - contests can be designed to generate highest revenue or to minimize social waste. For instance, in sporting tournaments it is often desirable to induce the players to spend the maximal amount of effort, or to induce an effort allocation that increases the chance of a close contest, with the objective of enhancing the excitement level of the tournament. Our experimental results indicate that this is best achieved by instituting intermediate prizes, and by making the contest more deterministic (i.e. reduce the random extraneous factors such as luck in determining the winner). In other rent seeking activities, such as political campaigns and patent races, the objective might be to minimize longdrawn contests and the accompanying wasteful expenditure. We find that it is best achieved by implementing only the grand prize (e.g., in U.S primaries, only the candidate to win a majority of 
their party delegates wins the party nomination; or in a patent race, only the first firm to finish the invention discovery process is awarded the patent protection).

To simplify the exposition we abstract from a number of issues that are nevertheless important in the field. For instance, we assume that there are only two players, and that they are symmetric. However, qualitative predictions of model do not change substantially when there are more than two players (Klumpp and Polborn, 2006). Furthermore, if one player has an exogenous advantage over the other, the ex ante advantage adds to the strategic momentum and further increases the probability of win by the skilled player.

Finally, although the focus of this paper has been comparative statics and pattern of effort, our results show that over-dissipation in contests is a robust phenomenon and is worthy of further investigation. We conjecture that best-of-three contests can provide a good platform for an explicit evaluation of some of the possible explanations for over-dissipation discussed above. This would involve both theoretical and experimental analysis. Theoretical work may be aimed at explaining the descriptive limitations of Nash equilibrium in these contests. For example, it may be possible to derive an evolutionary stable equilibrium for the entire best-of-three contest. Experimental investigation can then compare the predictions of this model to predictions based on the various competing explanations for over-dissipation. 


\section{References}

Alchian, A. 1950. Uncertainty, evolution and economic theory. Journal of Political Economy, 58, 211-221.

Amaldoss, W., and Rapoport, A. (2009). Excessive Expenditure in Two-Stage Contests: Theory and Experimental Evidence. In I. N. Hangen and A. S. Nilsen (Eds.), Game Theory: Strategies, Equilibria and Theorems , 241-266, Nova Science Publishers, NY.

Anderson, L. R., and Freeborn, B. A. (2010). Varying the intensity of competition in a multiple prize rent seeking experiment. Public Choice, 143, 237-254.

Anderson, L. R., and Stafford, S. L. (2003). An experiment analysis of rent seeking under varying competitive conditions. Public Choice, 115, 199-216.

Aronson, E. (1968). Dissonance Theory: Progress and Problems. In R. Abelson et al., eds, Theories of Cognitive Consistency: A Sourcebook, Rand McNally and Co, 5-27.Baharad, E., and Nitzan, S. (2008). Contest Efforts in Light of Behavioral Considerations. Economic Journal, 118, 2047-2059.

Baker, G., Gibbs, M., and Holmstrom, B. (1994a). The Internal Economics of the Firm: Evidence from Personnel Data. Quarterly Journal of Economics, 109, 881-919.

Baker, G., Gibbs, M., and Holmstrom, B. (1994b). The Wage Policy of a Firm. Quarterly Journal of Economics, 109, 921-955.

Baye, M., Kovenock, D., and de-Vries, C.G. (1996). The all-pay auction with complete information. Economic Theory, 8, 291-305.

Davis, D., and Reilly, R. (1998). Do too many cooks spoil the stew? An experimental Analysis of rent-seeking and the role of a strategic buyer. Public Choice, 95, 89- 115.

Dorsey-Palmateer, R., and Smith, G. (2004). Bowlers' hot hands. American Statistician, 58, 3845.

Ferrall, C., and Smith, A. (1999). A sequential game model of sports championship series: theory and estimation. Review of Economics and Statistics, 81, 704-719.

Festinger, L. (1957). A Theory of Cognitive Dissonance. Stanford: Stanford University Press.

Friedman, D., Pommerenke, K., Lukose, R., Milam, G., and Huberman, B.A. (2010) In search for the sunk cost fallacy. Experimental Economics, 10, 79-104

Fonseca, M. A. (2009). An experimental investigation of asymmetric contests. International Journal of Industrial Organization, 27, 582-591.

Hamilton, W. D. (1970). Selfish and spiteful behavior in evolutionary model. Nature, 228, 12181220.

Hehenkamp, B., Leininger, W., and Possajenikov, A. (2004). Evolutionary equilibrium in Tullock contests: spite and overdissipation. European Journal of Political Economy, 20, 1045-1057.

Hillman, A. L. and Katz, E. (1984). Risk averse rent-seekers and the social cost of monopoly power. Economic Journal, 94, 104-110.

Hirschleifer, J. (1995). Anarchy and its breakdown. Journal of Political Economy, 103, 26-52.

Holt, C. A. and Laury, S. (2002). Risk Aversion and Incentive Effects. The American Economic Review , 92,1644-1655.

Jackson, D. (1993). Independent trials are a model for disaster. Applied Statistics, 42, 211-220.

Kerick, S. E., Iso-Ahola, S. E. \& Hatfield, B. D. (2000). Psychological momentum in target shooting: Cortical, cognitive-affective, and behavioral responses. Journal of Sport \& Exercise Psychology, 22, 1-20. 
Klumpp, T., and Polborn, M.K. (2006). Primaries and the New Hampshire effect. Journal of Public Economics, 90, 1073-1114.

Konrad, K. A., and Schlesinger, H. (1997). Risk aversion in risk seeking and rent-augmenting games. The Economic Journal, 107, 1671-1683.

Konrad, K.A. (2009). Strategy and Dynamics in Contests. Oxford University Press.

Konrad, K.A., and Kovenock, D. (2009). Multi-battle contests. Games and Economic Behavior, 66, 256-274.

Leininger, W. (2003). On evolutionarily stable behavior in contests, Economics of Governance, 4, 177-186.

Lim, W., Matros, A., and Turocy, T.L. (2010). Raising Revenue with Lotteries: Theory and Experimental Evidence. Working Paper.

Malueg, D., and Yates, A. (2005). Equilibria and comparative statics in two player contests. European Journal of Political Economy, 21, 738-752.

Malueg, D., and Yates, A. (2010). Testing contest theory: evidence from best-of-three tennis matches. Review of Economics and Statistics, 92, 689-692.

McFall, T., Knoeber, C., and Thurman, W. (2009). Contests, grand prizes, and the hot hand. Journal of Sports Economics, 10, 236-255.

Millner, E. L. \& Pratt, M. (1991). Risk Aversion and Rent-Seeking: An Extension and Some Experimental Evidence. Public Choice, 69, 81-92.

Mosteller, F. (1952). The world series competition. Journal of the American Statistical Association, 47, 355-380.

Nitzan, S. (1991). Collective Rent Dissipation. The Economic Journal, 101, 1522-1534.

Parco J., Rapoport A., and Amaldoss W. (2005). Two-stage Contests with Budget Constraints: An Experimental Study. Journal of Mathematical Psychology, 49, 320-338.

Page, L. (2009). The momentum effect in competitions: field evidence from tennis matches, working paper, University of Westminster.

Potters, J., de Vries, C.G., and van Winden, F. (1998). An experimental examination of rational rent-seeking. European Journal of Political Economy, 14, 783 - 800.

Riechmann, T. (2007) An analysis of rent-seeking games with relative-payoff maximizers. Public Choice, 133, 147-155.

Schmitt, P., Shupp, R. Swope, K., and Cadigan, J. (2004). Multi-period rent-seeking contests with carryover: Theory and Experimental Evidence. Economics of Governance, 10, 247-259.

Sheremeta, R. M. (2010a). Contest Design: An Experimental Investigation. Economic Inquiry, forthcoming.

Sheremeta, R.M. (2010b). Experimental Comparison of Multi-Stage and One-Stage Contests. Games and Economic Behavior, 68, 731-747.

Sheremeta, R.M., and Zhang, J. (2010). Can Groups Solve the Problem of Over-Bidding in Contests? Social Choice and Welfare, 35, 175-197.

Treich, N. (2009). Risk-aversion and prudence in rent-seeking games. Public Choice, 1573-7101.

Tullock, G. (1980). Efficient Rent Seeking. In James M. Buchanan, Robert D. Tollison, Gordon Tullock, (Eds.), Toward a theory of the rent-seeking society. College Station, TX: Texas A\&M University Press, pp. 97-112.

Tversky, A., \& Kahneman, D. (1974). Judgment under uncertainty: Heuristics and biases. Science, 185, 1124-1130. 
Vallerand, R. J., Colavecchio, P. G., and Pelletier, L. G. (1988). Psychological momentum and performance inferences: a preliminary test of the antecedents-consequences psychological momentum model. Journal of Sport \& Exercise Psychology, 10, 92-108.

Vriend, N. J. (2000). An illustration if the essential difference between individual and social learning, and its consequences for computational analyses. Journal of Economic Dynamics and Control, 24, 1-19.

Weimann, J., Yang, C. -L., and Vogt, C. (2000). An experiment on sequential rent seeking. Journal of Economic Behavior and Organization, 41, 405-426. 
Table 1: Experimental Design and Predictions

\begin{tabular}{llll}
\hline \hline Treatments & $\mathrm{H}$ & $\mathrm{HI}$ & $\mathrm{LI}$ \\
\hline Final prize, $v$ & 100 & 100 & 100 \\
Intermediate prize, $d$ & 0 & 25 & 25 \\
Exponent, $r$ & 1 & 1 & 0.4 \\
\hline Equilibrium predictions & & & \\
\hline Effort in R1 & 16.4 & 21.2 & 7.5 \\
Effort in R2 by R1 winner & 14.1 & 22.0 & 7.5 \\
Effort in R2 by R1 loser & 4.7 & 13.2 & 7.5 \\
Effort in R3 by R2 winner & 25.0 & 31.3 & 12.5 \\
Effort in R3 by R2 loser & 25.0 & 31.3 & 12.5 \\
The probability of ending in R2 & 0.75 & 0.63 & 0.5 \\
Expected average effort & 32.0 & 50.5 & 21.3 \\
Expected payoff & 18.0 & 29.2 & 60.0 \\
\hline
\end{tabular}

Table 2: Summary Statistics

\begin{tabular}{|c|c|c|c|c|c|c|}
\hline Treatments & \multicolumn{2}{|c|}{$\overline{\mathrm{H}}$} & \multicolumn{2}{|c|}{$\overline{\mathrm{HI}}$} & \multicolumn{2}{|c|}{$\overline{\mathrm{LI}}$} \\
\hline Final prize, $v$ & \multicolumn{2}{|c|}{100} & \multicolumn{2}{|c|}{100} & \multicolumn{2}{|c|}{100} \\
\hline Intermediate prize, $d$ & \multirow{2}{*}{\multicolumn{2}{|c|}{$\begin{array}{l}0 \\
1\end{array}$}} & \multirow{2}{*}{\multicolumn{2}{|c|}{25}} & \multirow{2}{*}{\multicolumn{2}{|c|}{$\begin{array}{l}25 \\
04\end{array}$}} \\
\hline Exponent, $r$ & & & & & & \\
\hline & Equilibrium & Actual & Equilibrium & Actual & Equilibrium & Actual \\
\hline Effort in R1 & 16.4 & $22.2(0.6)$ & 21.2 & $27.2(0.6)$ & 7.5 & $22.3(0.4)$ \\
\hline Effort in $\mathrm{R} 2$ by $\mathrm{R} 1$ winner & 14.1 & $28.5(0.9)$ & 22.0 & $37.0(1.0)$ & 7.5 & $24.4(0.6)$ \\
\hline Effort in R2 by R1 loser & 4.7 & $23.5(1.0)$ & 13.2 & $28.1(0.9)$ & 7.5 & $23.3(0.6)$ \\
\hline Effort in R3 by R2 winner & 25.0 & $33.2(1.5)$ & 31.3 & $40.6(1.4)$ & 12.5 & $25.3(0.9)$ \\
\hline Effort in R3 by R2 loser & 25.0 & $31.7(1.5)$ & 31.3 & $38.1(1.3)$ & 12.5 & $24.3(0.8)$ \\
\hline The probability of ending in $\mathrm{R} 2$ & 0.75 & $0.61(0.02)$ & 0.63 & $0.58(0.02)$ & 0.5 & $0.51(0.02)$ \\
\hline Expected average effort & 32.0 & $60.8(1.5)$ & 50.5 & $76.3(1.5)$ & 21.3 & $58.2(1.0)$ \\
\hline Expected payoff & 18.0 & $-10.9(2.1)$ & 29.2 & $4.0(2.7)$ & 60.0 & $22.9(2.7)$ \\
\hline
\end{tabular}

Table 3: Lottery choices and Risk Aversion $(\mathbf{n}=\mathbf{1 0 0}) *$

\begin{tabular}{|c|c|c|c|c|c|c|c|c|}
\hline \multirow{3}{*}{$\begin{array}{c}\begin{array}{c}\text { Number } \\
\text { of Safe } \\
\text { Choices }\end{array} \\
0-1\end{array}$} & \multirow{2}{*}{$\begin{array}{l}\text { Range of Relative } \\
\text { Risk Aversion, } \rho\end{array}$} & \multirow[b]{2}{*}{ Risk Preference } & \multicolumn{6}{|c|}{ Percentage of Subject and Total Effort } \\
\hline & & & \multicolumn{2}{|c|}{$\begin{array}{l}\text { HI Treatment } \\
\quad(\mathrm{n}=640)\end{array}$} & \multicolumn{2}{|c|}{$\begin{array}{l}\mathrm{H} \text { treatment } \\
(\mathrm{n}=700)\end{array}$} & \multicolumn{2}{|c|}{$\begin{array}{l}\text { LI Treatment } \\
\quad(\mathrm{n}=660)\end{array}$} \\
\hline & $\rho<-1.73$ & & 0.0 & & 2.9 & 57.8 & 0.0 & \\
\hline 2 & $-1.73<\rho<-1.10$ & & 0.0 & & 0.0 & & 0.0 & \\
\hline 3 & $-1.10<\rho<-0.73$ & & 0.0 & & 0.0 & & 0.0 & \\
\hline 4 & $-0.73<\rho<-0.46$ & Risk loving & 0.0 & & 0.0 & & 0.0 & \\
\hline 5 & $-0.46<\rho<-0.26$ & & 6.3 & 71.9 & 2.9 & 83.3 & 3.0 & 26.5 \\
\hline 6 & $-0.26<\rho<-0.10$ & & 6.3 & 78.9 & 2.9 & 86.4 & 6.1 & 56.7 \\
\hline 7 & $-0.10<\rho<0.04$ & Risk neutral & 15.6 & 75.8 & 14.3 & 67.3 & 15.2 & 49.7 \\
\hline 8 & $0.04<\rho<0.17$ & & 9.4 & 94.2 & 14.3 & 50.8 & 18.2 & 61.5 \\
\hline 9 & $0.17<\rho<0.27$ & & 15.6 & 69.0 & 14.3 & 72.5 & 21.2 & 58.1 \\
\hline 10 & $0.27<\rho<0.37$ & & 28.1 & 71.4 & 22.9 & 61.1 & 15.6 & 55.3 \\
\hline 11 & $0.37<\rho<0.46$ & Risk averse & 6.3 & 90.4 & 8.9 & 52.6 & 3.03 & 75.1 \\
\hline 12 & $0.46<\rho<0.54$ & & 6.3 & 62.5 & 8.9 & 48.7 & 15.12 & 73.2 \\
\hline 13 & $0.54<\rho<0.61$ & & 6.3 & 80.0 & 0.0 & & 0.0 & \\
\hline 14 & $0.61<\rho<0.68$ & & 0.0 & & 5.7 & 63.6 & 3.0 & 30.5 \\
\hline 15 & $0.68<\rho$ & & 0.0 & & 2.9 & 30.2 & 0.0 & \\
\hline
\end{tabular}

*We dropped 8 subjects who were inconsistent in switching between Option A and Option B. Number of subjects (n) is 32 in $\mathrm{HI}$ treatment, 35 in the $\mathrm{H}$ treatment and 33 in the LI treatment. 
Figure 1: Total Effort over all 20 periods

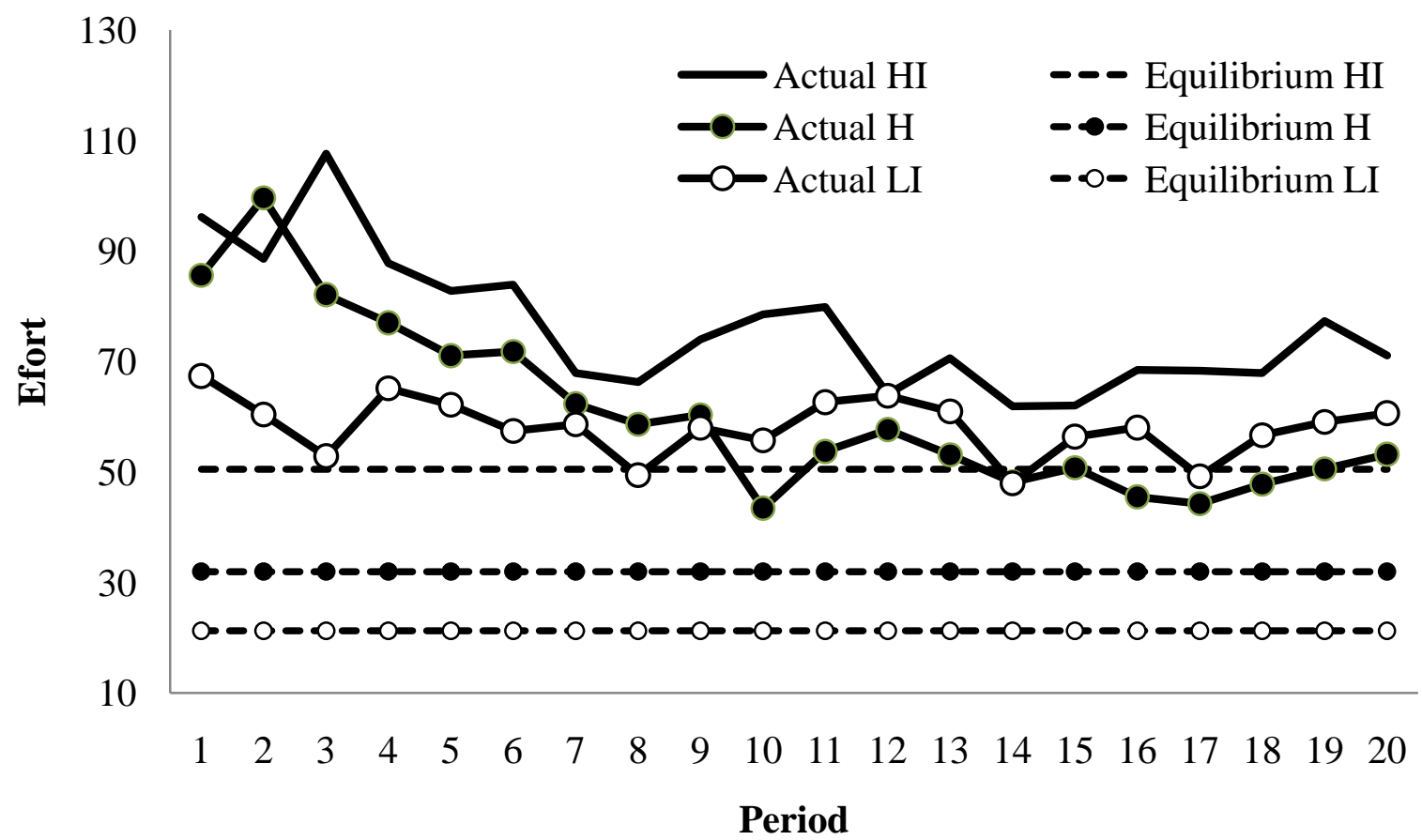

Figure 2: Effort across 3 rounds (HI Treatment)

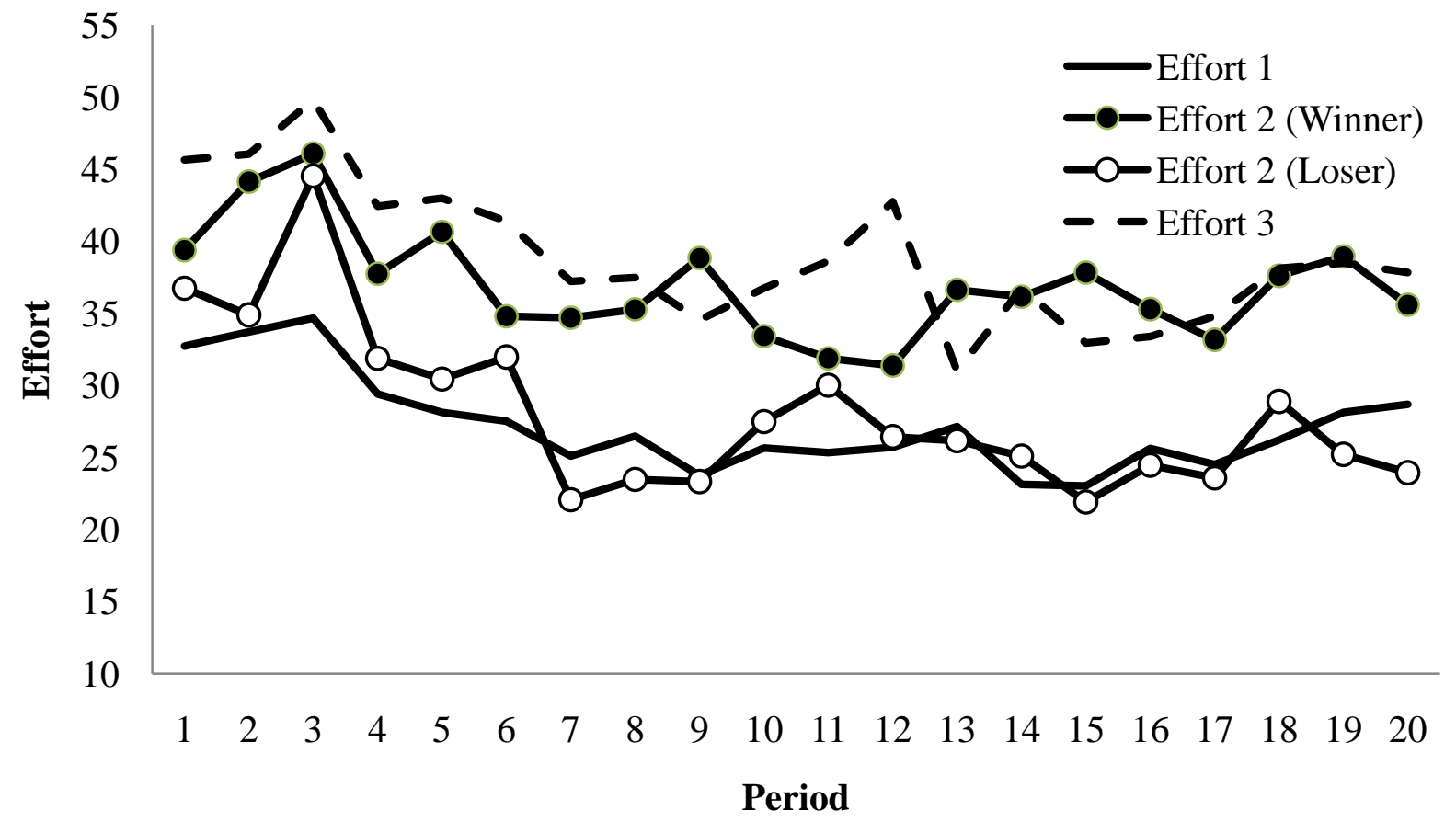




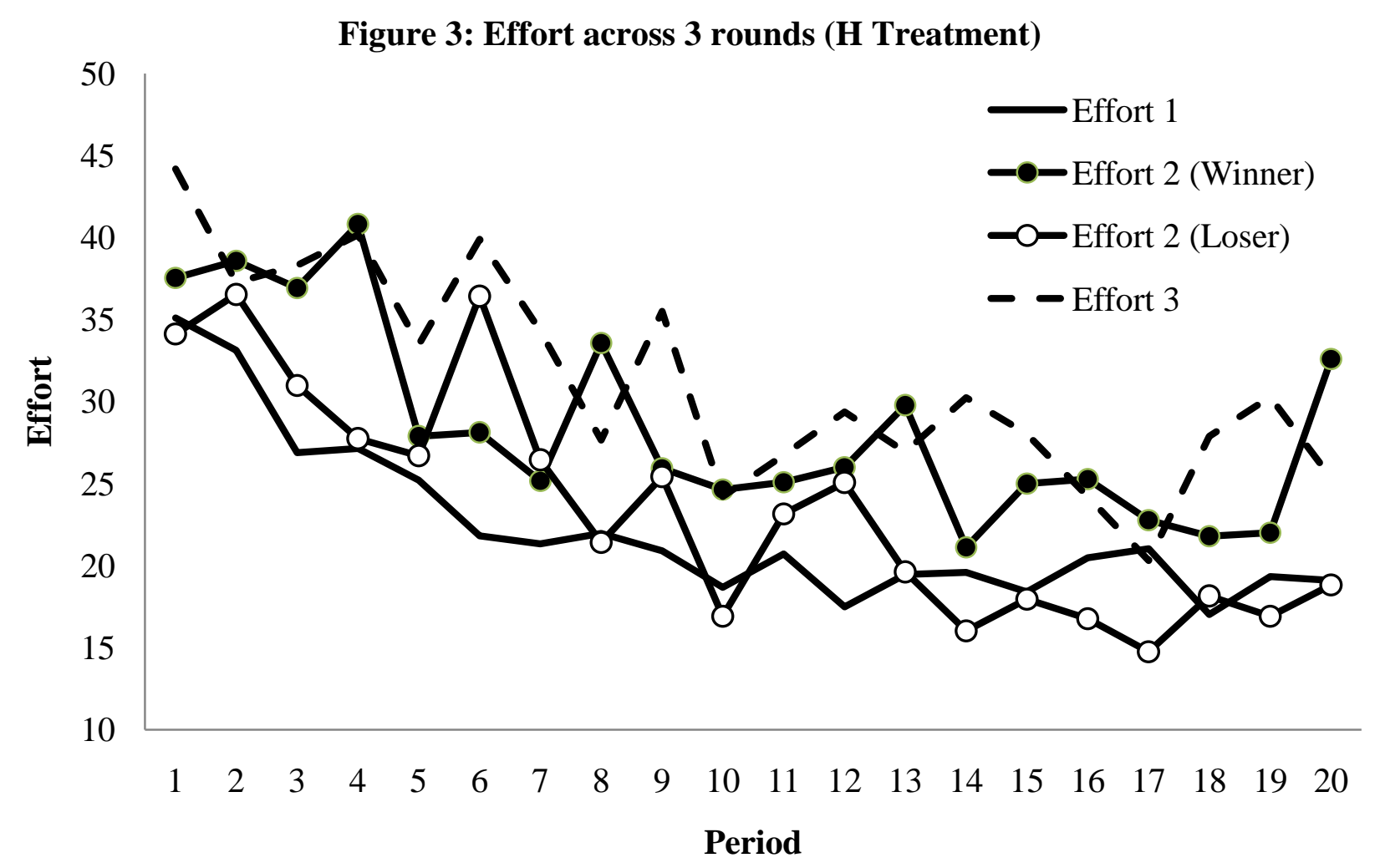

Figure 4: Effort across 3 rounds (LI Treatment)

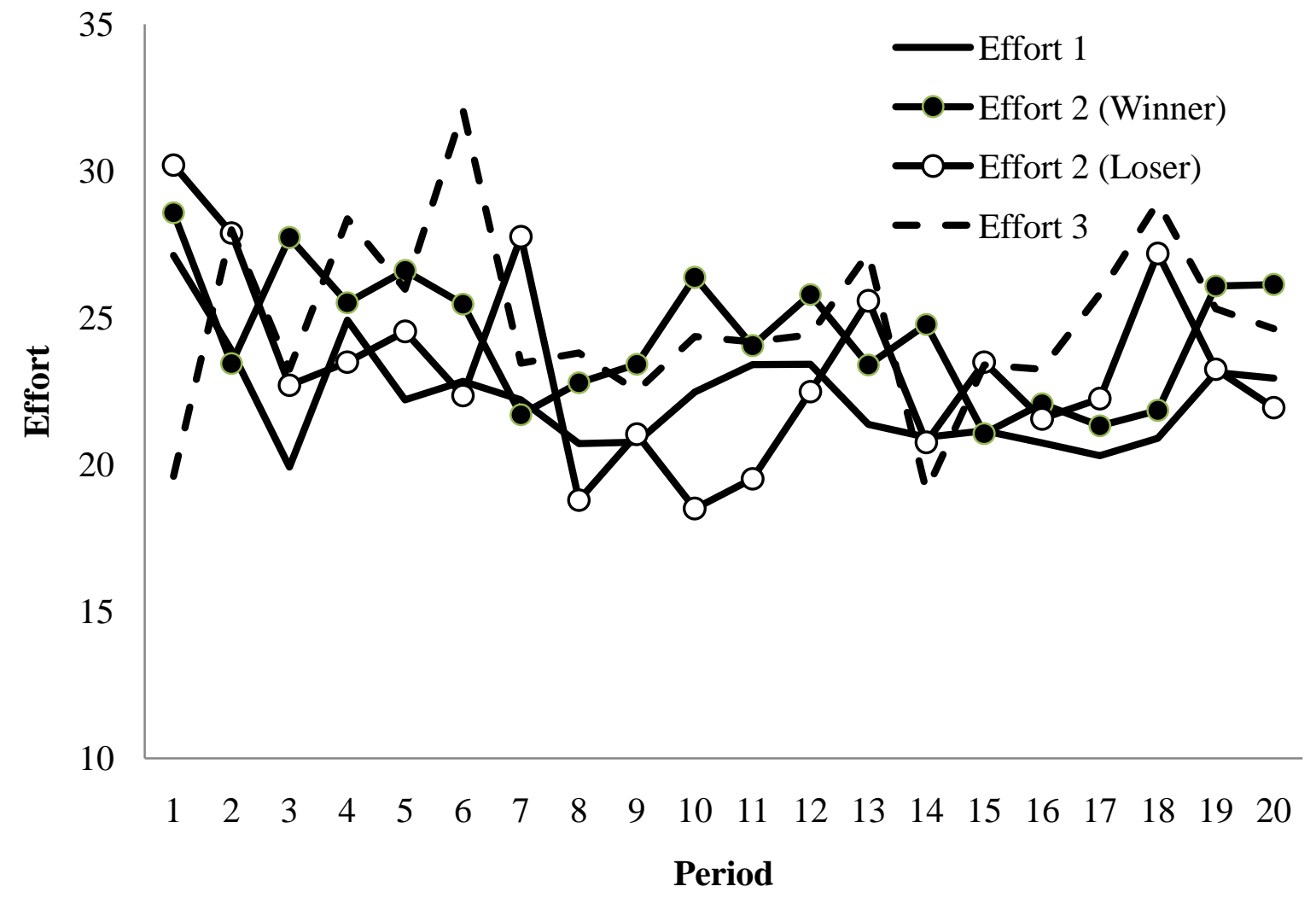


Figure 5: Total Effort by Individual Subjects across Treatments

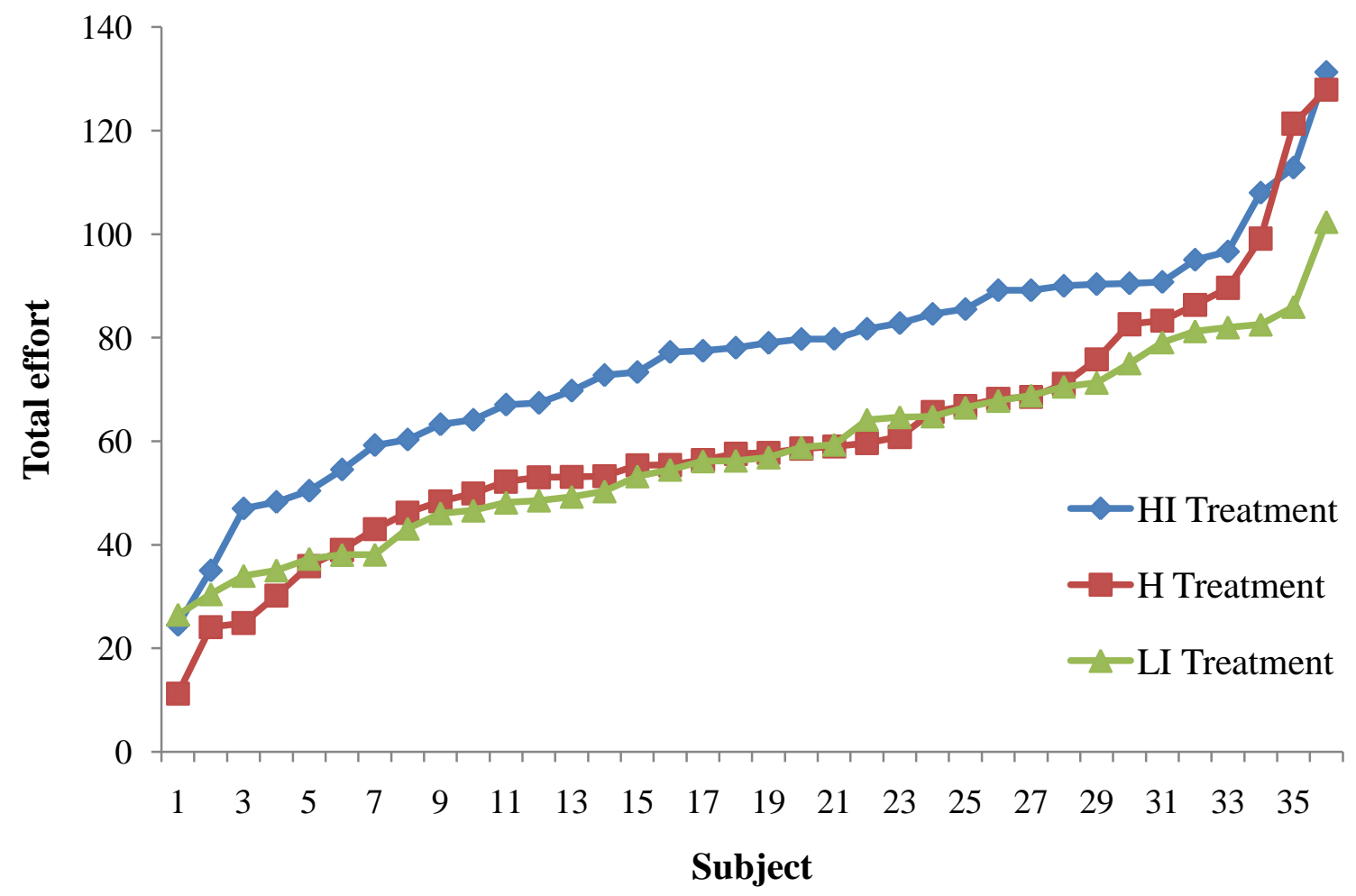




\section{Appendix - Instructions for HI Treatment (Not for Publication)}

\section{GENERAL INSTRUCTIONS}

This is an experiment in the economics of strategic decision making. Various research agencies have provided funds for this research. The instructions are simple. If you follow them closely and make appropriate decisions, you can earn an appreciable amount of money.

The experiment will proceed in two parts. Each part contains decision problems that require you to make a series of economic choices which determine your total earnings. The currency used in Part 1 of the experiment is U.S. Dollars. The currency used in Part 2 of the experiment is francs. These francs will be converted to U.S. Dollars at a rate of $\mathbf{2 5}$ francs to $\_$ up fee of \$7.00). Your earnings from both Part 1 and Part 2 of the experiment will be incorporated into your participation fee. At the end of today's experiment, you will be paid in private and in cash. There are $\mathbf{1 2}$ participants in today's experiment.

It is very important that you remain silent and do not look at other people's work. If you have any questions, or need assistance of any kind, please raise your hand and an experimenter will come to you. If you talk, laugh, exclaim out loud, etc., you will be asked to leave and you will not be paid. We expect and appreciate your cooperation.

\section{INSTRUCTIONS FOR PART 1}

In this part of the experiment you will be asked to make a series of choices in decision problems. How much you receive will depend partly on chance and partly on the choices you make. The decision problems are not designed to test you. What we want to know is what choices you would make in them. The only right answer is what you really would choose.

For each line in the table in the next page, please state whether you prefer option A or option B. Notice that there are a total of $\mathbf{1 5}$ lines in the table but only one line will be randomly selected for payment. Each line is equally likely to be selected, and you do not know which line will be selected when you make your choices. Hence you should pay attention to the choice you make in every line. After you have completed all your choices a token will be randomly drawn out of a bingo cage containing tokens numbered from 1 to 15. The token number determines which line is going to be selected for payment.

Your earnings for the selected line depend on which option you chose: If you chose option A in that line, you will receive $\mathbf{\$ 1}$. If you chose option B in that line, you will receive either $\mathbf{\$ 3}$ or $\mathbf{\$ 0}$. To determine your earnings in the case you chose option B there will be second random draw. A token will be randomly drawn out of the bingo cage now containing twenty tokens numbered from 1 to 20. The token number is then compared with the numbers in the line selected (see the table). If the token number shows up in the left column you earn $\$ 3$. If the token number shows up in the right column you earn $\$ 0$.

While you have all the information in the table, we ask you that you input all your 15 decisions into the computer. The actual earnings for this part will be determined at the end of part 2, and will be independent of part 2 earnings.

\begin{tabular}{|c|c|c|c|c|}
\hline $\begin{array}{l}\text { Deci } \\
\text { sion } \\
\text { no. }\end{array}$ & $\begin{array}{l}\text { Opti } \\
\text { on A }\end{array}$ & & $\begin{array}{c}\text { Option } \\
\text { B }\end{array}$ & $\begin{array}{l}\text { Please } \\
\text { choose } \\
A \text { or } B\end{array}$ \\
\hline 1 & $\$ 1$ & $\mathbf{\$ 3}$ never & $\$ 0$ if $1,2,3,4,5,6,7,8,9,10,11,12,13,14,15,16,17,18,19,20$ & \\
\hline 2 & $\$ 1$ & $\$ 3$ if 1 comes out of the bingo cage & $\$ 0$ if $2,3,4,5,6,7,8,9,10,11,12,13,14,15,16,17,18,19,20$ & \\
\hline 3 & $\$ 1$ & $\$ 3$ if 1 or 2 & $\$ 0$ if $3,4,5,6,7,8,9,10,11,12,13,14,15,16,17,18,19,20$ & \\
\hline 4 & $\$ 1$ & $\$ 3$ if $1,2,3$ & $\$ 0$ if $4,5,6,7,8,9,10,11,12,13,14,15,16,17,18,19,20$ & \\
\hline 5 & $\$ 1$ & $\$ 3$ if $1,2,3,4$ & $\$ 0$ if $5,6,7,8,9,10,11,12,13,14,15,16,17,18,19,20$ & \\
\hline 6 & $\$ 1$ & $\$ 3$ if $1,2,3,4,5$ & $\$ 0$ if $6,7,8,9,10,11,12,13,14,15,16,17,18,19,20$ & \\
\hline 7 & $\$ 1$ & $\$ 3$ if $1,2,3,4,5,6$ & $\mathbf{\$ 0}$ if $7,8,9,10,11,12,13,14,15,16,17,18,19,20$ & \\
\hline 8 & $\$ 1$ & $\$ 3$ if $1,2,3,4,5,6,7$ & $\$ 0$ if $8,9,10,11,12,13,14,15,16,17,18,19,20$ & \\
\hline 9 & $\$ 1$ & $\$ 3$ if $1,2,3,4,5,6,7,8$ & $\$ 0$ if $9,10,11,12,13,14,15,16,17,18,19,20$ & \\
\hline 10 & $\$ 1$ & $\$ 3$ if $1,2,3,4,5,6,7,8,9$ & $\$ 0$ if $10,11,12,13,14,15,16,17,18,19,20$ & \\
\hline 11 & $\$ 1$ & $\$ 3$ if $1,2,3,4,5,6,7,8,9,10$ & $\$ 0$ if $11,12,13,14,15,16,17,18,19,20$ & \\
\hline 12 & $\$ 1$ & $\$ \mathbf{3}$ if $1,2,3,4,5,6,7,8,9,10,11$ & $\$ 0$ if $12,13,14,15,16,17,18,19,20$ & \\
\hline 13 & $\$ 1$ & $\$ \mathbf{3}$ if $1,2,3,4,5,6,7,8,9,10,11,12$ & $\$ 0$ if $13,14,15,16,17,18,19,20$ & \\
\hline 14 & $\$ 1$ & $\mathbf{\$ 3}$ if $1,2,3,4,5,6,7,8,9,10,11,12,13$ & $\$ 0$ if $14,15,16,17,18,19,20$ & \\
\hline 15 & $\$ 1$ & $\$ 3$ if $1,2,3,4,5,6,7,8,9,10,11,12,13,14$ & $\$ 0$ if $15,16,17,18,19,20$ & \\
\hline
\end{tabular}




\section{INSTRUCTIONS FOR PART 2 \\ YOUR DECISION}

The second part of the experiment consists of $\mathbf{2 0}$ decision-making periods. The 12 participants in today's experiment will be randomly re-matched every period into 6 groups with 2 participants in each group. Therefore, the specific person who is the other participant in your group will change randomly after each period. The group assignment is anonymous, so you will not be told which of the participants in this room are assigned to your group

Each period consists of a maximum of three rounds. The period ends when one of the participants wins two of the three rounds ("best of three"). Thus, each period will consist of either two or three rounds. In each round, you and the other participant in your group will simultaneously make a bid (any number, including 0.1 decimal points). Your bid in each round cannot exceed 100 francs. The more you bid, the more likely you are to win a particular round. This will be explained in more detail later. Your earnings depend on the number of rounds you won and how many francs you spent on bidding. An example of your decision screen is shown below in Figure 1:

Figure 1 - Decision Screen

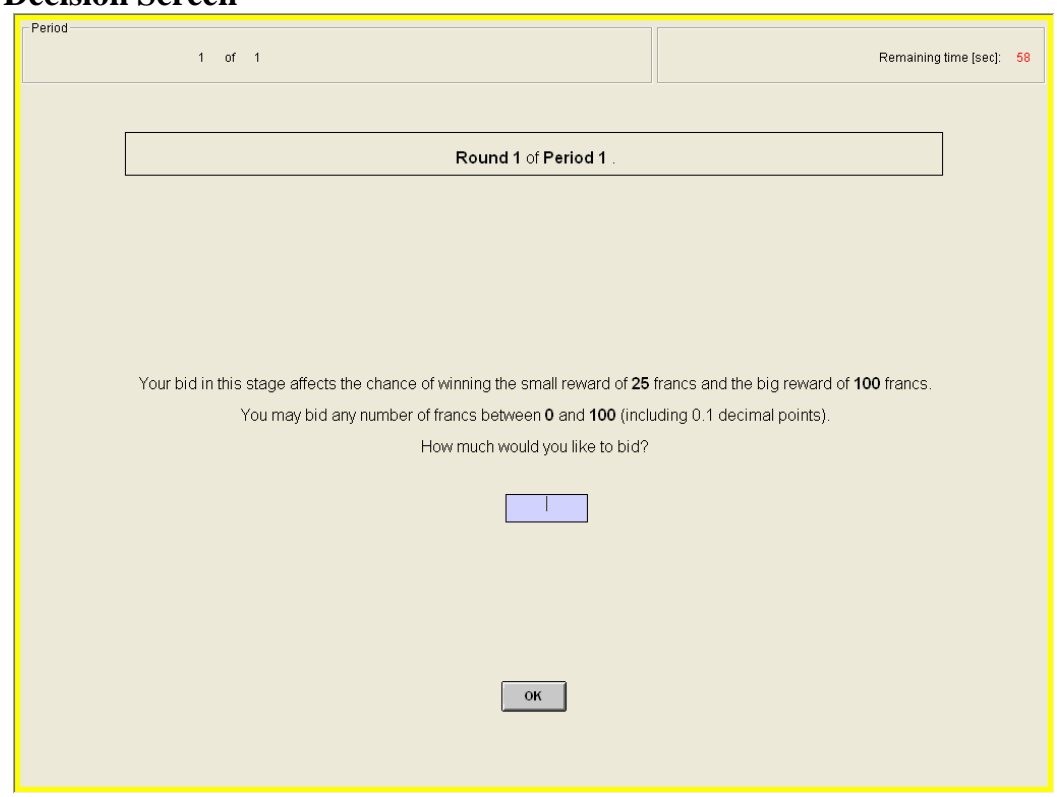

There are two types of rewards that you may receive during each period: big reward and small reward. The big reward is worth $\mathbf{1 0 0}$ francs and the small reward is worth $\mathbf{2 5}$ francs to you and the other participant in your group. The winner of an individual round will receive the small reward, while the participant who is first to win two rounds receives, in addition, the big reward. The period ends as soon as the big reward winner is determined.

\section{CHANCE OF WINNING A ROUND}

You can never guarantee that you will win a round. However, the greater your bid relative to the other participant's bid, the greater your probability of winning the round. That is, the more you bid, the more likely you are to win a round. The more the other participant in your group bids, the less likely you are to win a round. Specifically, your chance of winning a round is given by the following expression.

Your chance of (Your Bid)

winning a round $\quad=\quad($ Your Bid $)+($ The Other Participant's Bid $)$

Think of this in the following way. For each franc you bid you will receive lottery tickets. For example, if you bid 10 francs and the other participant bid 20 francs, you will receive 10 lottery tickets and the other participant will receive 20 lottery tickets. At the end of each round the computer draws randomly one ticket among all the tickets purchased by you and the other participant in your group. The owner of the drawn ticket wins the round. In the example above, your chance of winning the round is $0.33=10 /(10+20)$ and the other participant's chance of winning is $0.67=20 /(10+20)$. Note that your chance of winning a round is proportional to the amount of lottery tickets purchased by you and the other participant.

In the sheet attached to these instructions, you will find a probability table. This table will give you some idea of how your bid and the other participant's bid affect your chance of winning. For instance, suppose you bid 50 francs and the other participant bid 30 francs then your chance of winning the round is 0.63 . Note that as stated before, your chance of winning increases as your bid increases relative to the other participant's bid. So if you bid 
70 francs and the other participant is still bidding 30 francs, your chance of winning increases to 0.70 . To assist you with calculation of more precise numbers, we will provide you with the Excel calculator in each round. You may use the calculator to find the chance of winning for any combination of your bid and the other participant's bid. We will have a few practice rounds with the Excel calculator before the start of the experiment.

\section{YOUR EARNINGS}

Your earnings depend on the number of rounds you won and how many francs you spent on bidding in each round. For each round you win you receive a small reward. The participant who is first to win two rounds receives, in addition, the big reward. One of the four payment scenarios is possible:

(1) If the period lasted for only two rounds

(1a) Earnings of the participant who won both rounds are $=$ $=($ big reward $)+(2 \times$ small reward $)-($ bid in round 1$)-($ bid in round 2$)$

$=100+2 \times 25-($ bid in round 1$)-($ bid in round 2$)$

(1b) Earnings of the participant who won neither rounds are $=$ $=0-($ bid in round 1$)-($ bid in round 2$)$

(2) If the period lasted for three rounds

(2a) Earnings of the participant who won two rounds are $=$ $=($ big reward $)+(2 \times$ small reward $)-($ bid in round 1$)-($ bid in round 2$)-($ bid in round 3$)$

$=100+2 \times 25-($ bid in round 1$)-($ bid in round 2$)-($ bid in round 3$)$

(2b) Earnings of the participant who won one round are $=$ $=(1 \times$ small reward $)-($ bid in round 1$)-($ bid in round 2$)-($ bid in round 3$)$ $=1 \times 25-($ bid in round 1$)-($ bid in round 2$)-($ bid in round 3$)$

Please note that regardless of who wins the round, both participants will have to pay their bids.

\section{END OF THE ROUND}

After both participants make their round bids, the computer will make a random draw which will determine the winner of the round. Both participants will observe the outcome of the round - your bid, other participant's bid and winner, as shown in Figure 2. Then they make bids in another round. This continues until one of the participants in the group wins two rounds.

Figure 2 - Intermediate Screen

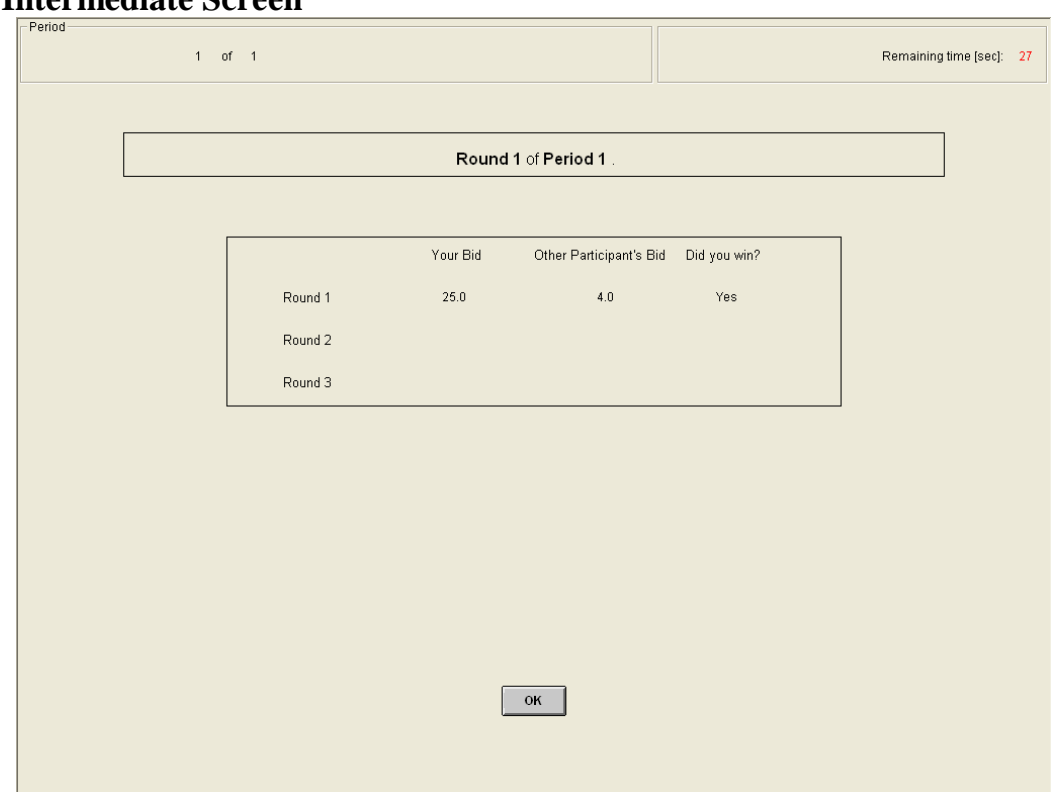

\section{END OF THE PERIOD}

The period ends when one of the participants in the group wins two rounds. At the end of the period, the computer will calculate your period earnings based on the number of rounds you won and how many francs you spent on bidding in each round. Your earnings from that period will be reported on the outcome screen as shown in Figure 3. Once the outcome screen is displayed you should record your results for the period on your Personal 
Record Sheet under the appropriate heading. You will be randomly re-matched with a different participant at the start of the next period.

Figure 3 - Outcome Screen

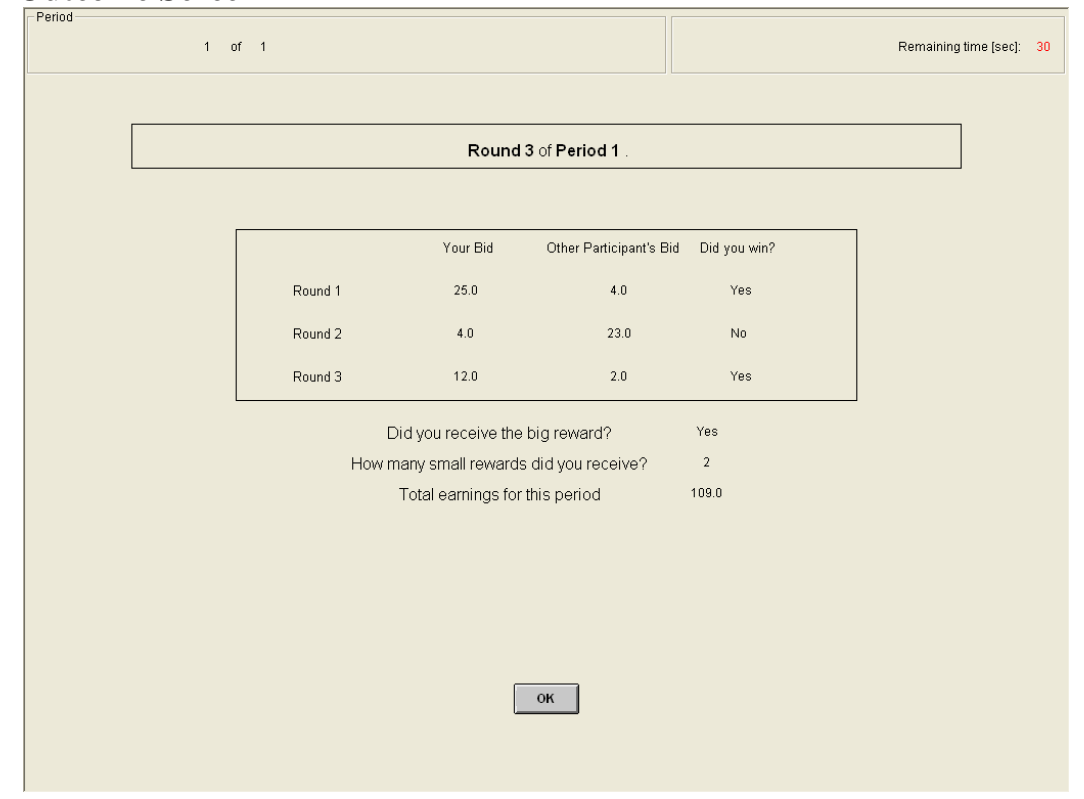

\section{END OF THE EXPERIMENT}

At the end of the experiment we will use the bingo cage to randomly select 2 out of 20 periods for actual payment. Depending on the outcome in a given period, you may receive either positive or negative earnings. You will sum the total earnings for these 2 periods and convert them to a U.S. dollar payment, as shown on the last page of your personal record sheet. Remember you have already received a \$20.00 participation fee (equivalent to $\mathbf{5 0 0}$ francs). If your earnings from this part of the experiment are positive, we will add them to your participation fee. If your earnings are negative, we will subtract them from your participation fee.

Are there any questions?

Before we begin this part of the experiment, we request that you fill the following questionnaire. The only purpose of the questionnaire is to check your understanding of the instructions. The experiment will start as soon as everyone has completed the questionnaire and we have addressed any doubts or concerns. We will start with a few practice rounds with the Excel probability calculator. 


\section{Economic Science Institute Working Papers}

2010

10-21 Kimbrough, E. and Sheremeta, R. Make Him an Offer He Can't Refuse: Avoiding Conflicts Through Side Payments.

10-20 Savikhim, A. and Sheremeta, R. Visibility of Contributions and Cost of Inflation: An Experiment on Public Goods.

10-19 Sheremeta, R. and Shields, T. Do Investors Trust or Simply Gamble?

10-18 Deck, C. and Sheremeta, R. Fight or Flight? Defending Against Sequential Attacks in the Game of Siege.

10-17 Deck, C., Lin, S. and Porter, D. Affecting Policy by Manipulating Prediction Markets: Experimental Evidence.

10-16 Deck, C. and Kimbrough, E. Can Markets Save Lives? An Experimental Investigation of a Market for Organ Donations.

10-15 Deck, C., Lee, J. and Reyes, J. Personality and the Consistency of Risk Taking Behavior: Experimental Evidence.

10-14 Deck, C. and Nikiforakis, N. Perfect and Imperfect Real-Time Monitoring in a Minimum-Effort Game.

10-13 Deck, C. and Gu, J. Price Increasing Competition? Experimental Evidence.

10-12 Kovenock, D., Roberson, B.,and Sheremeta, R. The Attack and Defense of Weakest-Link Networks.

10-11 Wilson, B., Jaworski, T., Schurter, K. and Smyth, A. An Experimental Economic History of Whalers' Rules of Capture.

10-10 DeScioli, P. and Wilson, B. Mine and Thine: The Territorial Foundations of Human Property.

10-09 Cason, T., Masters, W. and Sheremeta, R. Entry into Winner-Take-All and Proportional-Prize Contests: An Experimental Study.

10-08 Savikhin, A. and Sheremeta, R. Simultaneous Decision-Making in Competitive and Cooperative Environments.

10-07 Chowdhury, S. and Sheremeta, R. A generalized Tullock contest.

10-06 Chowdhury, S. and Sheremeta, R. The Equivalence of Contests. 
10-05 Shields, T. Do Analysts Tell the Truth? Do Shareholders Listen? An Experimental Study of Analysts' Forecasts and Shareholder Reaction.

10-04 Lin, S. and Rassenti, S. Are Under- and Over-reaction the Same Matter? A Price Inertia based Account.

10-03 Lin, S. Gradual Information Diffusion and Asset Price Momentum.

10-02 Gjerstad, S. and Smith, V. Household expenditure cycles and economic cycles, 1920 - 2010.

10-01 Dickhaut, J., Lin, S., Porter, D. and Smith, V. Durability, Re-trading and Market Performance.

2009

09-11 Hazlett, T., Porter, D., Smith, V. Radio Spectrum and the Disruptive Clarity OF Ronald Coase.

09-10 Sheremeta, R. Expenditures and Information Disclosure in Two-Stage Political Contests.

09-09 Sheremeta, R. and Zhang, J. Can Groups Solve the Problem of Over-Bidding in Contests?

09-08 Sheremeta, R. and Zhang, J. Multi-Level Trust Game with "Insider" Communication.

09-07 Price, C. and Sheremeta, R. Endowment Effects in Contests.

09-06 Cason, T., Savikhin, A. and Sheremeta, R. Cooperation Spillovers in Coordination Games.

09-05 Sheremeta, R. Contest Design: An Experimental Investigation.

09-04 Sheremeta, R. Experimental Comparison of Multi-Stage and One-Stage Contests.

09-03 Smith, A., Skarbek, D., and Wilson, B. Anarchy, Groups, and Conflict: An Experiment on the Emergence of Protective Associations.

09-02 Jaworski, T. and Wilson, B. Go West Young Man: Self-selection and Endogenous Property Rights.

09-01 Gjerstad, S. Housing Market Price Tier Movements in an Expansion and Collapse.

2008

08-10 Dickhaut, J., Houser, D., Aimone, J., Tila, D. and Johnson, C. High Stakes Behavior with Low Payoffs: Inducing Preferences with Holt-Laury Gambles.

08-09 Stecher, J., Shields, T. and Dickhaut, J. Generating Ambiguity in the Laboratory.

08-08 Stecher, J., Lunawat, R., Pronin, K. and Dickhaut, J. Decision Making and Trade without Probabilities.

08-07 Dickhaut, J., Lungu, O., Smith, V., Xin, B. and Rustichini, A. A Neuronal Mechanism of Choice. 
08-06 Anctil, R., Dickhaut, J., Johnson, K., and Kanodia, C. Does Information Transparency Decrease Coordination Failure?

08-05 Tila, D. and Porter, D. Group Prediction in Information Markets With and Without Trading Information and Price Manipulation Incentives.

08-04 Caginalp, G., Hao, L., Porter, D. and Smith, V. Asset Market Reactions to News: An Experimental Study.

08-03 Thomas, C. and Wilson, B. Horizontal Product Differentiation in Auctions and Multilateral Negotiations.

08-02 Oprea, R., Wilson, B. and Zillante, A. War of Attrition: Evidence from a Laboratory Experiment on Market Exit.

08-01 Oprea, R., Porter, D., Hibbert, C., Hanson, R. and Tila, D. Can Manipulators Mislead Prediction Market Observers? 